\title{
Crocus Sativus L. Flower Aqueous Extract as Corrosion Inhibitor of Tinplate (Cans Material) in $0.5 \mathrm{M} \mathrm{H}_{2} \mathrm{C}_{2} \mathrm{O}_{4}$ Medium
}

\author{
Amal Boumezzourh ${ }^{1}$, Mohamed Ouknin ${ }^{1 \mathbb{D}}$, El-mustapha Chibane ${ }^{1 \mathbb{D}}$, Abdelhamid Bouyanzer ${ }^{2}{ }^{\mathbb{D}}$, Zaid $^{-}$ \\ Faska $^{1}$, Jean Costa ${ }^{3}$ (D), Lhou Majidi ${ }^{1, *}$ (D) \\ 1 Laboratory of Natural Substances Synthesis and Molecular Dynamics, Faculty of Sciences and Techniques, Moulay Ismail \\ University, Errachidia, Morocco \\ 2 Mohamed Premier University, Laboratory of Applied Chemistry and Environment, Faculty of Sciences, Oujda, Morocco \\ 3 CNRS UMR 6134 Laboratoire des Produits Naturels, Université de Corse, 20250- Corte, France \\ * Correspondence: 1majidi@yahoo.fr, lmajidi@fst.umi.ac.ma (L.M.);
}

Scopus Author ID 15760507800

Received: 17.04.2021; Revised: 15.05.2021; Accepted: 18.05.2021; Published: 10.06.2021

\begin{abstract}
This study aims at finding a new solution against food cans corrosion. The effect of the aqueous extract of Crocus Sativus flower after the recuperation of the stigma against cans material (tinplate) corrosion in $0.5 \mathrm{M} \mathrm{H}_{2} \mathrm{C}_{2} \mathrm{O}_{4}$, was evaluated using the gravimetric, electrochemical and SEMEDX analysis. The results show that the studied extract reduces the corrosion effect proportionally to the concentration used to reach its highest inhibition efficiency of $87.3 \%$ at $3 \mathrm{~g} . \mathrm{L}^{-1}$ of CS extract; this is undoubtedly linked to the chemical composition of the studied extract. The adsorption of the extracted compounds on the tinplate surface follows the Langmuir isotherm. The extract behavior at a temperature between 303 and 373K shows that the extract exhibits good inhibition over a range of moderate to high temperatures. Analysis of the tinplate surface using scanning electron microscopy and energy dispersive $\mathrm{X}$-rays (SEM-EDX) confirms adsorption of oxygenated molecules and verifies that the surface is significantly improved in the extract's presence compared with that exposed to the acid medium.
\end{abstract}

Keywords: Crocus sativus; extract; tinplate; food; corrosion; inhibitor.

(C) 2021 by the authors. This article is an open-access article distributed under the terms and conditions of the Creative Commons Attribution (CC BY) license (https://creativecommons.org/licenses/by/4.0/).

\section{Introduction}

The combination of the strength and formability of steel with the good appearance and corrosion resistance of tin makes tinplate the most widely used material in the manufacture of beverage and food cans. However, the interaction between cans content and tin leads to a stannic reaction (divalent type, $\mathrm{Sn}^{4+}$, tin IV), which reveals a toxic effect [1]. The dissolution of the tinplate depends on the food matrix, the acidity, the presence of oxidizing reagents (anthocyanin, nitrate, iron and copper), as well as the presence of air (oxygen) in the headspace, duration and storage temperature. The highest concentrations are found in processed food and canned foods, which are the main source of human exposure to tin. In this way, the Codex Alimentarius Commission identifies tin as a priority food contaminant [2], causing serious health problems like gastrointestinal disturbances and other toxicity problems [3]. Numerous studies were conducted to increase the corrosion resistance of tinplate and prevent the dissolution of tin by food media, such as lacquers or passivation treatment [4-6]. For instance, the use of inhibitors represents one of the solutions adopted to prevent the material's corrosion. 
In fact, various natural substances have been tested as green inhibitors of tinplate corrosion in different corrosive environments. Among these substances, which show an inhibitory effect against this corrosion, we can cite the essential oils of Thymus satureioides [7], onion oil [8], Artimisia [9], Mentha pulegium [10] and Ammodaucus leucotrichus [11].

Crocus sativus L. belongs to the Iridaceae family, which is the only genus Crocus to produce Saffron [12]. This is used in folk medicine as an antispasmodic, carminative, stomachic, expectorant, aphrodisiac, cardiotonic and stimulant. Saffron is most often used as a food coloring and as a flavoring agent in the food industry [13]. In Morocco, saffron production is estimated at 3 tons per year, corresponding to $5 \%$ of world production. With traditional cultivation, the average yield of one hectare of saffron don't exceed 2 to $3 \mathrm{~kg}^{-h^{-1}}$, but these yields can easily reach more than $10 \mathrm{~kg} \cdot \mathrm{ha}^{-1}$ using well-followed developed techniques. Currently, most of the Crocus sativus flower is discarded and only a small amount of stigmas is left; one kilogram of complete flowers produces 70 to $80 \mathrm{~g}$ of fresh stigmas $(2 \mathrm{~g}$ of dry stigmas). Indeed, more than $90 \%$ of this flower (petals, stamens and the other parts) represents the saffron by-product with more than 10000 tons per year [14]. This huge amount of biomass remains untapped even though it contains molecules that can be used in different fields, such as pharmacy, food industry, perfumery, etc.

Farmers use the by-product of the saffron harvest to feed livestock or in some cases, to extract tincture [15]. Recently, some studies affirm that, after recovery stigmas (CS), the Crocus sativus flower represents a source of phenolic compounds having an important antioxidant activity $[14,16,17]$. On the one hand, chemical analysis of Crocus sativus shows that the safranal is the main volatile compound $[18,19]$. On the other, the Crocin, picrocrocin, and flavonols represent the main compounds of Crocus sativus extracts (Figure 1) [20, 21].

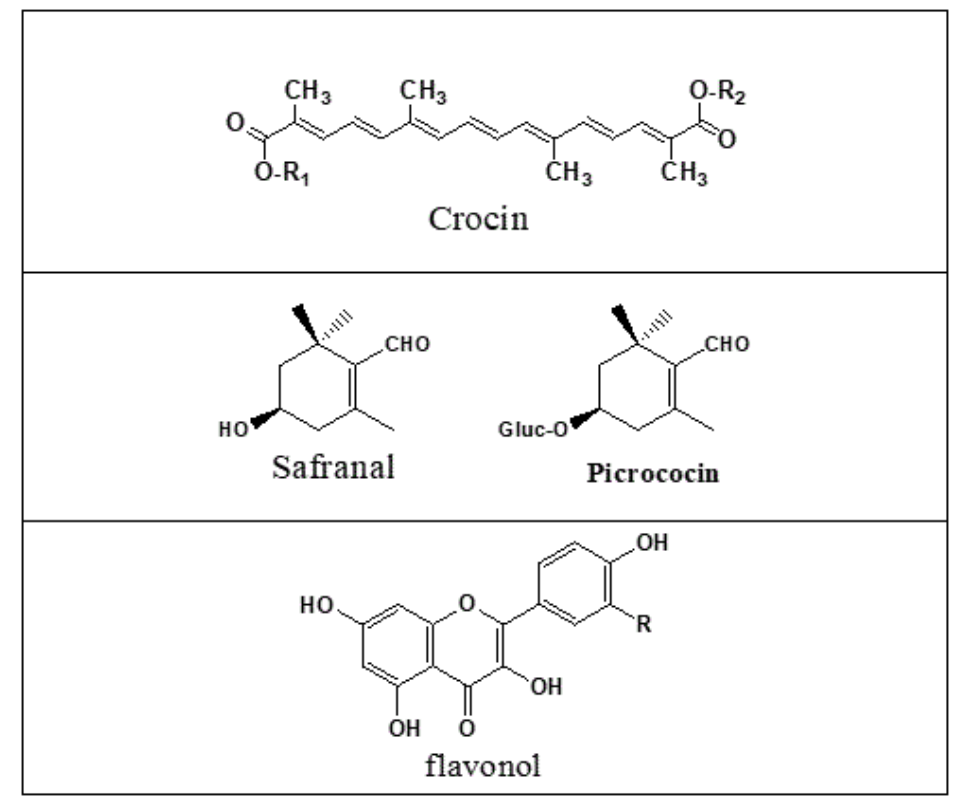

Figure 1. The chemical structure of Crocus sativus main compounds.

To valorize these by-products, we focused the search on a new inhibitor able to reduce the tinplate corrosion in the acid medium $[10,11]$. In this study, we are interested in evaluating the anti-corrosion proprieties of aqueous extract of stigma-free Crocus sativus flowers, using weight loss measurement, electrochemical impedance spectroscopy and electrochemical polarization measurements. In addition, the surface morphology was analyzed using scanning electron microscopy and energy dispersive X-rays (SEM-EDX). 


\section{Materials and Methods}

\subsection{Plant material and extract preparation.}

The Crocus sativus L. flowers were collected from Taznakht in the Draa-Tafilalet region (Morocco). After the recovery of stigmas, they were dried and stored in the dark at room temperature before grinding. For the preparation of the extract, $10 \mathrm{~g}$ of powder petals was stirred in $100 \mathrm{~mL}$ of distilled water at room temperature for $24 \mathrm{~h}$. After filtration of extract, the solvent was evaporated.

\subsection{Gravimetric test.}

The weight loss measurement is is performed under total immersion of tinplate $\left(1.5^{*} 1.5\right.$ $\mathrm{cm}^{2}$ ) with the chemical composition $\mathrm{Sn}(51.49 \%)$, Fe (47.23\%), Co (0.88\%) and $\mathrm{Al}(0.41 \%)$, in $50 \mathrm{~mL}$ of $0.5 \mathrm{M} \mathrm{H}_{2} \mathrm{C}_{2} \mathrm{O}_{4}$ solution with different concentrations of $\mathrm{CS}$ aqueous extract $(0.5$ to $3 \mathrm{~g} . \mathrm{L}^{-1}$ of extract). Before immersing tinplate sheets into the test solution, the sheets were rinsed with distilled water, digressed with ethanol then dried out and weighted. After $6 \mathrm{~h}$ of immersion at $303 \mathrm{~K}$, the tinplate sheets were rinsed, dried out and weighted. To evaluate the effect of temperature and the thermodynamic parameters, the same test was conducted in a temperature range of 303 to $374 \mathrm{~K}$ for $2 \mathrm{~h}$ of total immersion in the solution test medium.

The rate corrosion $\mathrm{W}\left(\mathrm{mg} \cdot \mathrm{cm}^{-2} \cdot \mathrm{h}^{-1}\right)$ is calculated according to the equation (1):

$$
W=\frac{\left(m_{0}-m_{i n h}\right)}{S . t}
$$

where $\mathrm{m}_{0}$ and $\mathrm{m}_{\mathrm{inh}}$ represent the sheets weight before and after immersion, $\mathrm{S}\left(\mathrm{cm}^{2}\right)$ represents the simple surface and $\mathrm{t}(\mathrm{h})$ the immersion duration.

The inhibition efficiency E\% is determined according to the equation (2):

$$
E \%=\left(\frac{W_{0}-W_{i n h}}{W_{0}}\right) \times 100
$$

where $\mathrm{W}_{0}$ and $\mathrm{W}_{\text {inh }}$ represent the corrosion rate in the absence and presence of inhibitor, respectively.

The coverage surface $\Theta$ is calculated using equation (3):

$$
\theta=\left(1-\frac{W_{i n h}}{W_{0}}\right)
$$

\subsection{Electrochemical impedance spectroscopy.}

The electrochemical study was realized at ambient temperature, using potentiostat Volta lab PGZ 100 piloted by Volta master software and connected to a cell with three electrodes. The saturated calomel electrode and platinum electrode were used as a reference and auxiliary electrode and the working electrode was presented by tinplate disc with a surface area of $0.5 \mathrm{~cm}^{2}$.

The working electrode was flushed with distilled water, wrung out with acetone, and dried before immersion in oxalic acid solution with different concentrations of aqueous extract of Crocus sativus. Before any measurement, the working electrode must be calibrated at open circuit potential (Eocp) for 30 minutes. 
The electrochemical impedance spectroscopy analysis was performed at rest potential Eocp, with sine wave voltage $(10 \mathrm{mV})$ peak to peak and frequency range with $100 \mathrm{KHz}$ as high limit and $10 \mathrm{mHz}$ as low limit. The value of $\mathrm{Cdl}$ and Rt were determined from the Nyquist plot.

The inhibition efficiency $\left(\mathrm{ER}_{\mathrm{R}}\right)$ is computed according to the following equation (4):

$$
E_{R}=\left(\frac{R_{\text {inh }}-R_{0}}{R_{\text {inh }}}\right) \times 100
$$

$\mathrm{R}_{\text {inh }}$ is the charge transfer in presence of CS extract and $\mathrm{R}_{0}$ is the charge transfer obtained for $0.5 \mathrm{M} \mathrm{H}_{2} \mathrm{C}_{2} \mathrm{O}_{4}$.

\subsection{Potentiodynamic polarization test.}

The potentiodynamic curves of tinplate in $0.5 \mathrm{M} \mathrm{C}_{2} \mathrm{H}_{2} \mathrm{O}_{4}$ with different concentrations of CS extract were recorded at a scan rate of $1 \mathrm{mV} / \mathrm{sec}$ from the corrosion potential ( $\left.\mathrm{E}_{\text {corr }}\right)$. The corrosion current densities were obtained using the Tafel extrapolation method. The inhibition efficiency in function of corrosion current density $\left(\mathrm{E}_{\mathrm{I}} \%\right)$ is calculated according to the followed equation (5):

$$
E_{I} \%=\left(\frac{I_{0}-I_{\text {inh }}}{I_{0}}\right) \times 100
$$

$\mathrm{I}_{0}$ and $\mathrm{I}^{\text {inh }}$ represent the corrosion current densities in the presence and absence of CS aqueous extract, respectively.

\subsection{Scanning electron microscopy and energy dispersive X-rays (SEM-EDX).}

The surface morphology of tinplate after its immersion for $6 \mathrm{~h}$ in $0.5 \mathrm{M} \mathrm{H}_{2} \mathrm{C}_{2} \mathrm{O}_{4}$ solution with and without the addition of the optimal concentration of CS extract $\left(3 \mathrm{~g} . \mathrm{L}^{-1}\right)$ were evaluated by SEM-EDX using a TESCAN VEGA 3 EDAX instrument at an accelerating voltage of 20 $\mathrm{kV}$. The tinplate samples were cleaned with distilled water then dried before their visualization using SEM-EDX.

\section{Results and Discussion}

\subsection{Weight loss measurement.}

The inhibition effect of CS aqueous extract was evaluated using the weight loss measurement; this method is based on the weight of tinplate specimens before and after their emersion into the solution test. Table 1 and Figure 2 represent the corrosion rate and the inhibition efficiency in function of extract concentration.

Table 1. Weight loss measurement of tinplate in $0.5 \mathrm{M} \mathrm{H}_{2} \mathrm{C}_{2} \mathrm{O}_{4}$ with different concentrations of CS extract.

\begin{tabular}{c|c|c|c} 
Concentration $\left(\mathrm{g.L} \mathbf{-}^{-\mathbf{1}}\right)$ & $\mathrm{W}\left(\mathbf{m g} / \mathbf{c m}^{\mathbf{2}} \mathbf{. h}\right)$ & Ew (\%) & $\boldsymbol{\theta}$ \\
\hline $\mathbf{0 . 5} \mathbf{M ~ C}_{2} \mathrm{H}_{2} \mathbf{O}_{4}$ & 0.63 & - & - \\
\hline $\mathbf{0 . 5}$ & 0.24 & $\mathbf{6 1 . 9 0}$ & $\mathbf{0 . 6 1 9 0}$ \\
\hline $\mathbf{1}$ & 0.16 & $\mathbf{7 4 . 6 0}$ & $\mathbf{0 . 7 4 6 0}$ \\
\hline $\mathbf{2}$ & 0.11 & $\mathbf{8 2 . 5 4}$ & $\mathbf{0 . 8 2 5 4}$ \\
\hline $\mathbf{3}$ & 0.08 & $\mathbf{8 7 . 3 0}$ & $\mathbf{0 . 8 7 3 0}$
\end{tabular}




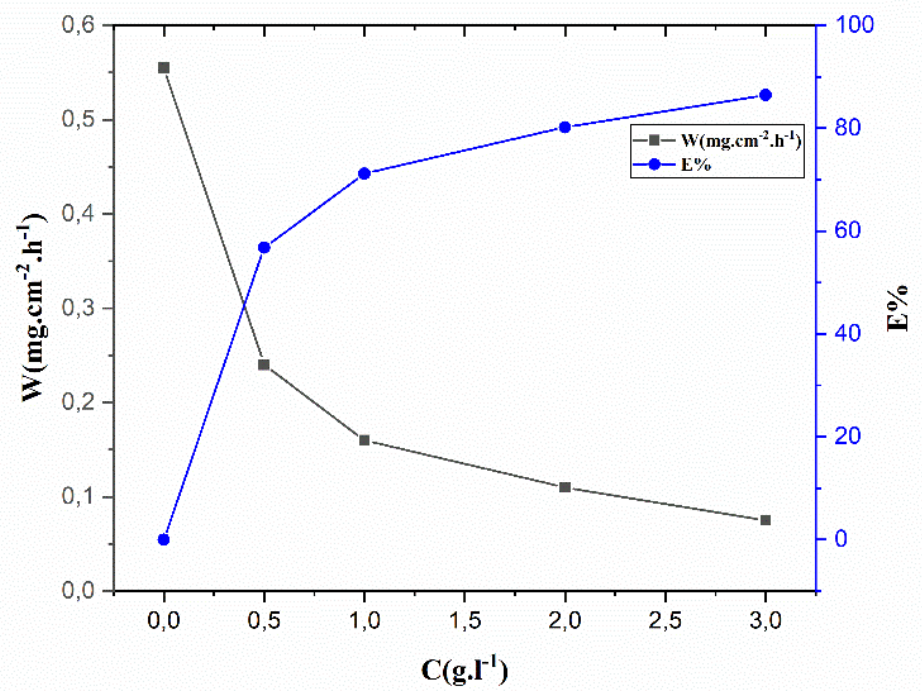

Figure 2. The variation of inhibition efficiency and rate corrosion of tinplate in $0.5 \mathrm{M} \mathrm{H}_{2} \mathrm{C}_{2} \mathrm{O}_{4}$ with different concentrations of CS extract.

As shown in Table 1 and Figure 2, the addition of CS to $0.5 \mathrm{M} \mathrm{H}_{2} \mathrm{C}_{2} \mathrm{O}_{4}$ reduces tinplate corrosion. As a matter of fact, the rate of corrosion decreases by increasing the concentration of CS used to reach its minimal value of $0.08 \mathrm{mg} . \mathrm{cm}^{-2} \cdot \mathrm{h}^{-1}$ while the optimum inhibition efficiency of $87.30 \%$ is observed at $3 \mathrm{~g} . \mathrm{L}^{-1}$. This effect could be explained by the blockage of tinplate corrosion sites by the adsorption of CS extract molecules on the tinplate surface.

\subsection{Impedance spectroscopy.}

The values of the electrochemical parameters, charge transfer resistance $\left(\mathrm{R}_{\mathrm{t}}\right)$, double layer capacity $\left(\mathrm{C}_{\mathrm{dl}}\right)$, and inhibitory efficiency $(\mathrm{E} \%)$ for different concentrations of the aqueous extract of CS are grouped in Table 2.

Table 2. Electrochemical impedance spectroscopy parameters of tinplate corrosion in $0.5 \mathrm{M} \mathrm{H}_{2} \mathrm{C}_{2} \mathrm{O}_{4}$ medium with different concentrations of CS extract.

\begin{tabular}{c|c|c|c}
$\mathbf{C}\left(\mathbf{g} . \mathbf{L}^{-\mathbf{1}}\right)$ & $\mathbf{R}_{\mathbf{t}}\left(\mathbf{o h m . \mathbf { c m } ^ { 2 } )}\right.$ & $\mathbf{C d l}\left(\boldsymbol{\mu} \mathbf{F . c m} \mathbf{c m}^{\mathbf{2}}\right)$ & $\mathbf{E} \%$ \\
\hline $0.5 \mathrm{M} \mathrm{H}_{2} \mathrm{C}_{2} \mathrm{O}_{4}$ & 40 & 90.2 & - \\
\hline 0.5 & 96.66 & 84.09 & 58.61784 \\
\hline 1 & 131.5 & 96.91 & 69.58175 \\
\hline 2 & 146.4 & 86.95 & 72.6776 \\
\hline 3 & 241.1 & 60.91 & 83.4093
\end{tabular}

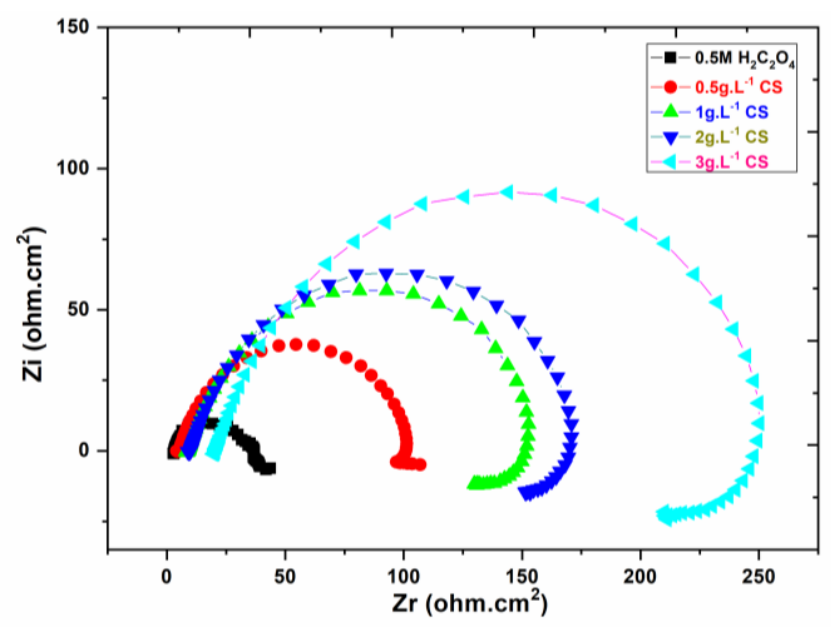

Figure 3. The Nyquist diagrams of tinplate in $0.5 \mathrm{M} \mathrm{H}_{2} \mathrm{C}_{2} \mathrm{O}_{4}$ with different concentrations of CS extract. 
According to the Nyquist diagrams presented in Figure 3, the obtained diagrams show similar shapes throughout all CS extract concentrations. This confirms that the addition of CS extract doesn't affect the corrosion mechanism of tinplate in the $0.5 \mathrm{M} \mathrm{H}_{2} \mathrm{C}_{2} \mathrm{O}_{4}$ medium, which is controlled by the charge transfer mechanism [22,23]. It's also clear that these loops are not perfect semicircles; this can be attributed to the frequency dispersion of the interfacial impedance or the heterogeneity of the electrode surface. This heterogeneity can result from roughness, impurities, dislocations, adsorption of the inhibitor and formation of porous layers [24]. In addition, the loop size grows by increasing the concentration used of CS extract, which reflects the increase of the charge transfer.

By analyzing the electrochemical results presented in Table 2. It should be noted that the concentration-dependent transfer resistance reaches its maximum value of $241.1 \mathrm{ohm} . \mathrm{cm}^{-2}$ at $3 \mathrm{~g} . \mathrm{L}^{-1}$, showing an inhibitory efficiency of $83.41 \%$. The rise in inhibitory efficiency and transfer resistance is associated with a decrease in the value of the double layer capacity; changed from 90 to $60 \mu \mathrm{F} . \mathrm{cm}^{2}$. This decrease can result from an increase in the thickness of the electrical double layer, which suggests that the CS extract functions by adsorption at the metal/solution interface. The change within the Cdl value is due to the adsorption of organic molecules on the tinplate surface and replacing the water molecules, indicating the formation of a protective film and reducing the degree of the metal dissolution [25].

\subsection{Polarization curves.}

Figure 4, illustrates the potentiodynamic polarization curves for tinplate electrodes in $0.5 \mathrm{M} \mathrm{H}_{2} \mathrm{C}_{2} \mathrm{O}_{4}$ at $303 \mathrm{~K}$ with and without the addition of different concentrations of Crocus sativus extract. The electrochemical parameters values are presented in Table 3.

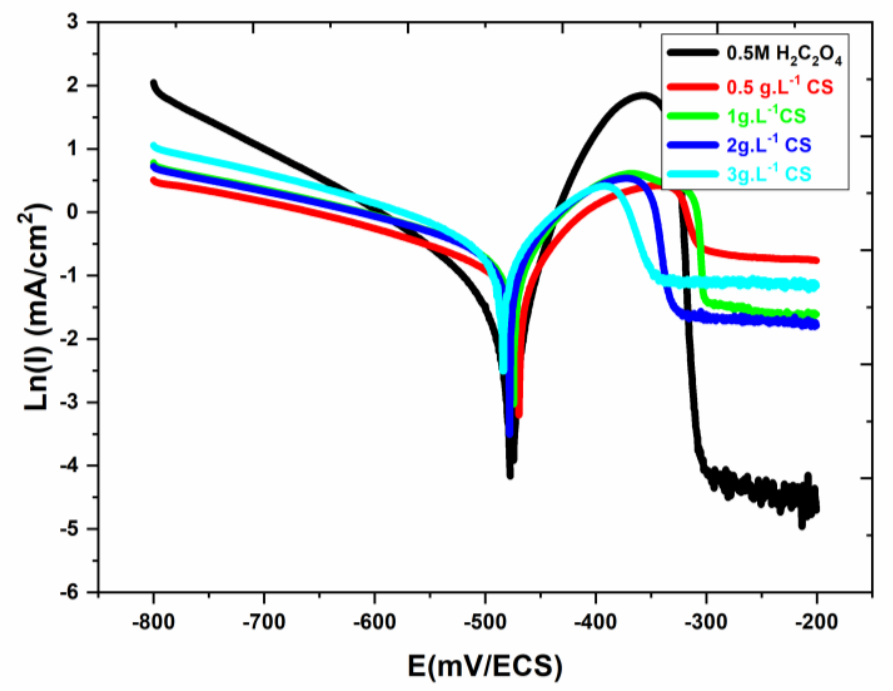

Figure 4. Polarization curves of tinplate in $0.5 \mathrm{M}$ oxalic acid in the presence of a different concentration of CS extract.

Table 3. The electrochemical parameters of tinplate corrosion in $0.5 \mathrm{M} \mathrm{H}_{2} \mathrm{C}_{2} \mathrm{O}_{4}$ with different concentrations of $\mathrm{CS}$ extract using the Potentiodynamic polarization method.

\begin{tabular}{c|c|c|c|c|c} 
Concentration $\left(\mathbf{g . L} \mathbf{L}^{-\mathbf{1}}\right)$ & $\mathbf{E}_{\mathbf{c o r r}}(\mathbf{m V} / \mathbf{S C E})$ & $\mathbf{I}_{\mathbf{c o r r}}\left(\mathbf{m A . c m} \mathbf{- n}^{-2}\right)$ & $\boldsymbol{\beta}_{\mathbf{a}}(\mathbf{m V} / \mathbf{d e c})$ & $\boldsymbol{\beta}_{\mathbf{c}}(\mathbf{m V} / \mathbf{d e c})$ & $\mathbf{E} \%$ \\
\hline $0.5 \mathrm{M}$ & -553.50 & 1.12 & 55.10 & -227.90 & - \\
\hline 0.5 & -485 & 0.3743 & 68.8 & -202.8 & 66.47 \\
\hline 1 & -479.6 & 0.2768 & 71.6 & -245.3 & 75.21 \\
\hline 2 & -476.1 & 0.2479 & 64.8 & -226.4 & 77.79 \\
\hline 3 & -471 & 0.1448 & 68.9 & -222.9 & 87.03
\end{tabular}


According to Figure 4, which represents the polarization curves of tinplate in $0.5 \mathrm{M}$ $\mathrm{H}_{2} \mathrm{C}_{2} \mathrm{O}_{4}$ medium with different concentrations of CS aqueous extract, it is clear that the anodic current density (Icorr) decreases in the presence of the extract and that the latter modifies the mechanism of hydrogen evolution and the anodic dissolution of the tinplate in the study medium. The results represented in Table 3, show that the addition of CS extract decreases corrosion current density. As result, the inhibition efficiency (E\%) increases to its high value of $87.03 \%$ at $3 \mathrm{~g} . \mathrm{L}^{-1} \mathrm{CS}$ extract. On the other hand, the irregular trends of $\beta \mathrm{a}$ and $\beta \mathrm{c}$ are caused by the adsorption of more than one type of species on the tinplate surface, which is often attributed to the chemical composition of the extract studied [26]. Furthermore, for a displacement in Ecorr higher than $85 \mathrm{mV}$ for system inhibited with reference to the uninhibited, the inhibitor is recognized as cathodic or anodic type. For a displacement less than $85 \mathrm{mV}$, the inhibitor is of mixed type. For our case, the CS extract is considered a mixed-type inhibitor $[27,28]$.

\subsection{Adsorption isotherm.}

The CS compounds inhibit the corrosion of tinplate by their adsorption on the metal surface, causing a displacement of water molecules and their replacement by the inhibitor. However, the inhibitor adsorption depends on several factors such as the metal surface nature, the varying degrees of surface site activity, the medium temperature and the electronic characteristics of the inhibitor [29, 30]. Different models were evaluated to understand the adsorption of CS extract on tinplate surface adsorption isotherm. Different models were evaluated, such as Langmuir, Temkin, Frumkin, and Freundlich.

To determine the isotherm adsorption of CS extract on the tinplate surface, a graphical relationship between the inhibitor concentration Cinh and $\mathrm{Cinh} / \theta$, is drawn and shown in Figure 5. A straight line with almost unit (1.04) and correlation coefficient $\left(\mathrm{R}^{2}=0.9994\right)$ is obtained, which confirms that the adsorption of the CS extract compounds follows the Langmuir isothermal adsorption model. This suggests that the inhibitor is adsorbed on a tinplate surface without interaction between the adsorbed molecules while forming a monolayer [30,31].

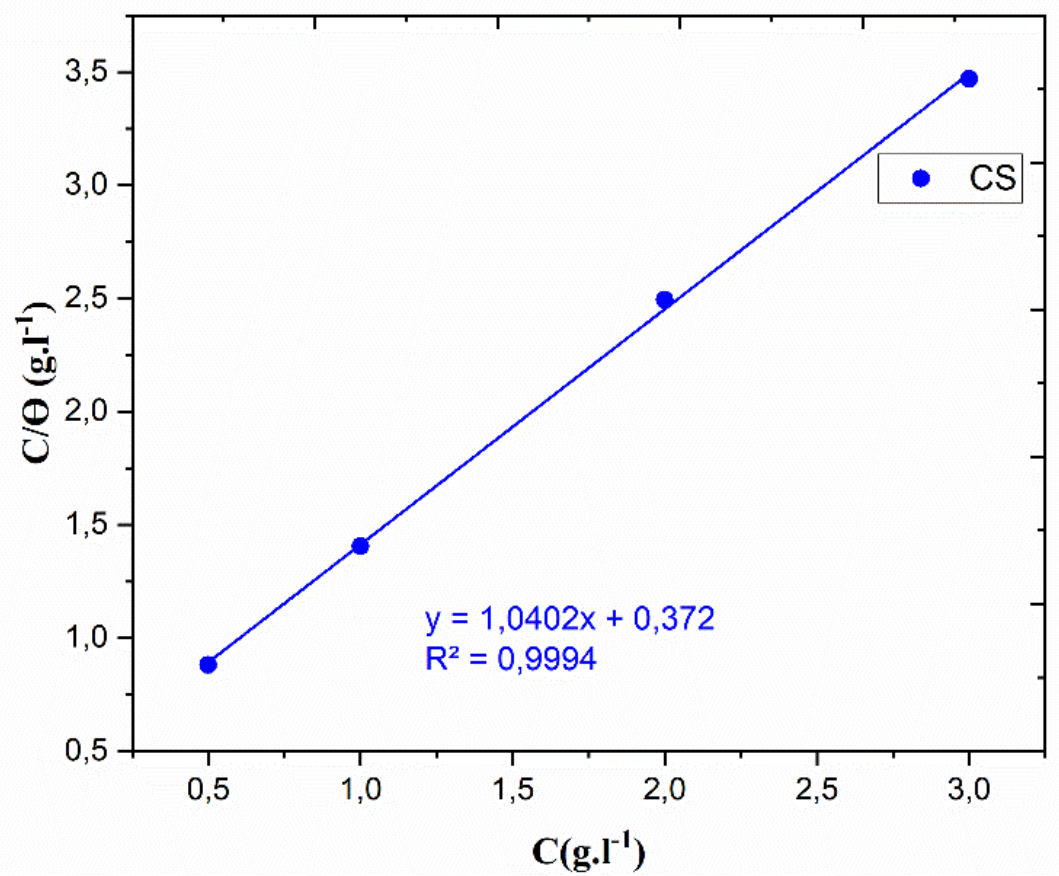

Figure 5. Langmuir isotherm for CS extract adsorption on tinplate surface at 303K. 


\subsection{Temperature effect.}

The temperature very influences the inhibition reaction, the latter can modify the interaction between the metal and the medium, such as rupture, also by desorption, decomposition and/or rearrangement of the inhibitor [32]. To evaluate the temperature effect on the tinplate corrosion in $0.5 \mathrm{M} \mathrm{H}_{2} \mathrm{C}_{2} \mathrm{O}_{4}$ in the presence of $3 \mathrm{~g} . \mathrm{L}^{-1}$ of $\mathrm{CS}$ extract, gravimetric analysis was carried out at a temperature range of 303 to $373 \mathrm{~K}$. The results obtained are gathered in Table 4.

Table 4. Temperature effect on tinplate corrosion in $0.5 \mathrm{M} \mathrm{C}_{2} \mathrm{H}_{2} \mathrm{O}_{4}$ solution with $3 \mathrm{~g} .1^{-1}$ of CS extract.

\begin{tabular}{c|c|c|c}
\multirow{2}{*}{$\mathbf{T}(\mathbf{K})$} & $\mathbf{0 . 5} \mathbf{M ~ H}_{2} \mathbf{C}_{2} \mathbf{O}_{\mathbf{4}}$ & \multicolumn{2}{|c}{$\mathbf{C S}$} \\
\cline { 2 - 4 } & $\mathrm{W}\left(\mathrm{mg} \cdot \mathrm{cm}^{-2} \cdot \mathrm{h}^{-1}\right)$ & $\mathrm{W}\left(\mathrm{mg} \cdot \mathrm{cm}^{-2} \cdot \mathrm{h}^{-1}\right)$ & $\mathrm{E} \%$ \\
\hline $\mathbf{3 0 3}$ & 0.55 & 0.075 & 86.48 \\
\hline $\mathbf{3 1 3}$ & 0.78 & 0.15 & 81.25 \\
\hline $\mathbf{3 2 3}$ & 1 & 0.21 & 79.67 \\
\hline $\mathbf{3 4 3}$ & 1.5 & 0.35 & 71
\end{tabular}

According to Table 4, which shows the gravimetric analysis of tinplate in $0.5 \mathrm{M} \mathrm{H}_{2} \mathrm{C}_{2} \mathrm{O}_{4}$ with the optimum concentration of CS extract at various temperatures, it is clear that the corrosion rate increases with increasing temperature even in the presence of the CS extract. Hence, a decrease in the inhibition efficiency goes from $86.48 \%$ at $303 \mathrm{~K}$ to $71 \%$ at $373 \mathrm{~K}$. This effect can be attributed to the desorption rate, which is parallel to the adsorption one. As a result, the tinplate surface becomes less protected and the inhibitor loses its effectiveness partially.

The effect of temperature on the corrosion process in inhibited and uninhibited media explains the behavior of the metal/solution interface. The Arrhenius law can be presented as a straight line of the logarithm of the corrosion rate (W) and 1/T according to the following equations 6 and 7 :

$$
\begin{aligned}
W & =K \exp \left(-E_{a} / R T\right) \\
W & =\frac{R T}{N h} \cdot \exp \left(\frac{\Delta S_{a}}{R}\right) \cdot \exp \left(\frac{-\Delta H_{a}}{R T}\right)
\end{aligned}
$$

$\mathrm{W}$ represents the tinplate rate corrosion, Ea is the apparent activation energy, $\Delta \mathrm{S}_{\mathrm{a}}$ is the activation entropy, $\Delta \mathrm{H}_{\mathrm{a}}$ represents the activation enthalpy, $\mathrm{K}$ is the Arrhenius pre-exponential factor, $\mathrm{h}$ is the Plank's constant and $\mathrm{N}$ is the Avogadro's number.

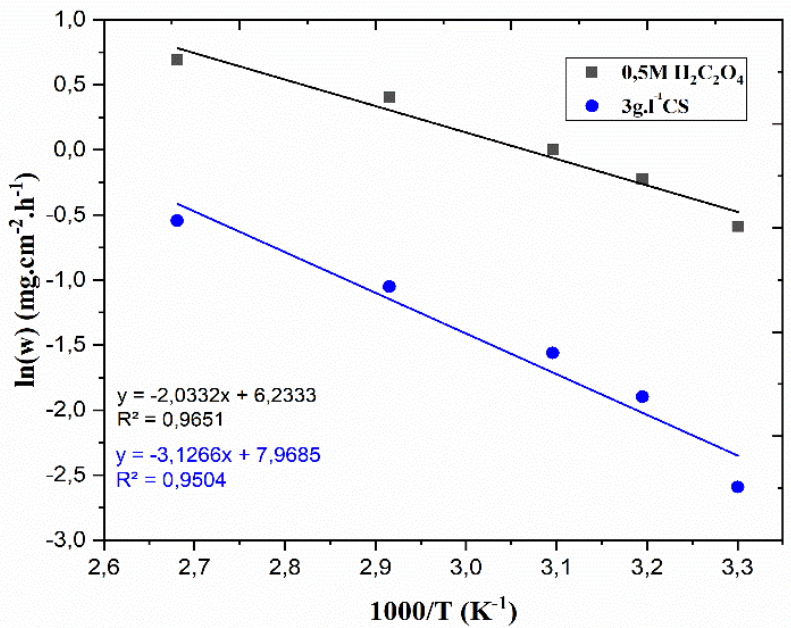

Figure 6. Arrhenius plots of tinplate in $0.5 \mathrm{M} \mathrm{H}_{2} \mathrm{C}_{2} \mathrm{O}_{4}$ medium with and without the addition of $3 \mathrm{~g} . \mathrm{L}^{-1}$ of $\mathrm{CS}$ extract. 


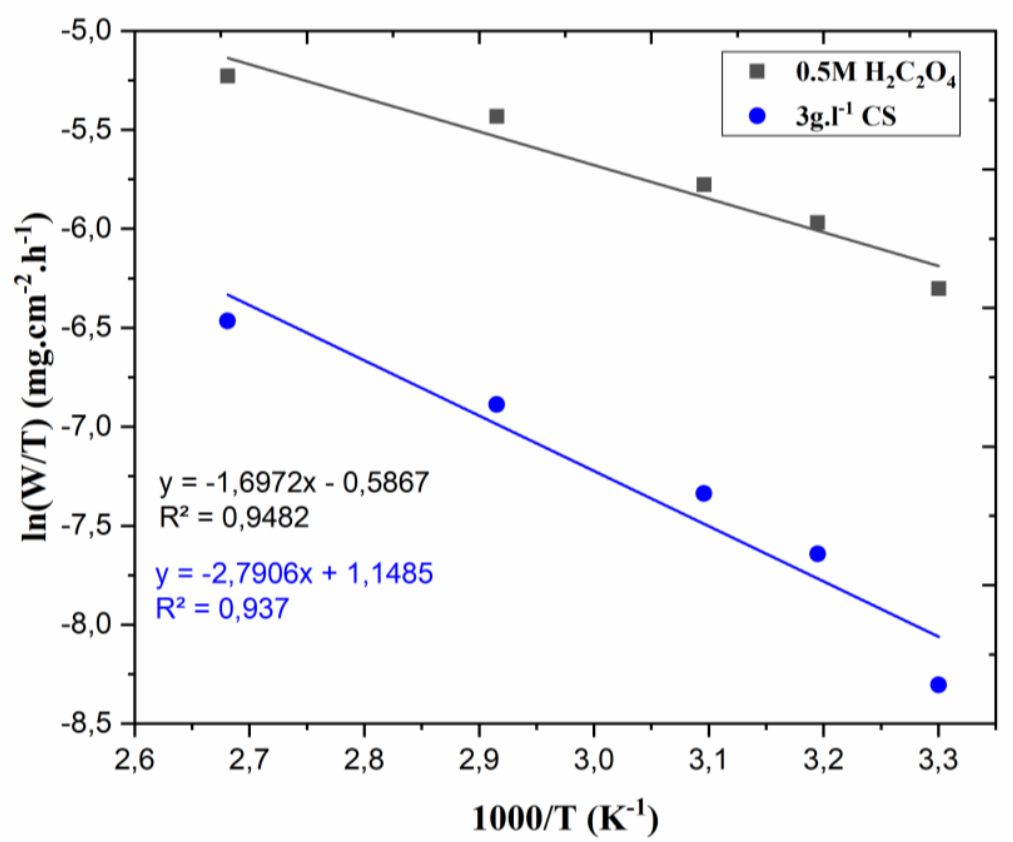

Figure 7. Arrhenius transition plots of tinplate in $0.5 \mathrm{M} \mathrm{H}_{2} \mathrm{C}_{2} \mathrm{O}_{4}$ medium with and without the addition of $3 \mathrm{~g} . \mathrm{L}^{-1}$ of CS extract.

The slope of straight lines of Arrhenius plots Figures 6 corresponding to (-Ea/R), which allows us to calculate the activation energy values. For the enthalpy $\Delta \mathrm{Ha}$ and the entropy of activation $\Delta \mathrm{S}_{\mathrm{a}}$, they are determined from the slope $\left(\Delta \mathrm{H}_{\mathrm{a}} / \mathrm{R}\right)$ and from the intercept $\left(\operatorname{lnR} / \mathrm{Nh}+\Delta \mathrm{S}_{\mathrm{a}} / \mathrm{R}\right)$ of straight lines in Figure 7 .

Table 5. Activation parameters of tinplate corrosion in $0.5 \mathrm{M} \mathrm{H}_{2} \mathrm{C}_{2} \mathrm{O}_{4}$ with and without the addition of $3 \mathrm{~g} . \mathrm{L}^{-1}$ of

\begin{tabular}{|c|c|c|c|c|}
\hline \multicolumn{5}{|c|}{ CS extract. } \\
\hline & $\underset{\left(\mathbf{k J} . \mathrm{mol}^{-1}\right)}{\mathbf{E a}}$ & $\begin{array}{c}\Delta H^{\circ} \\
\left(\mathbf{k J} . \mathrm{mol}^{-1}\right)\end{array}$ & $\begin{array}{c}\Delta S^{\circ} \\
\left(\mathbf{k J} . \mathrm{mol}^{-1}\right)\end{array}$ & $\begin{array}{c}\mathrm{Ea}-\Delta \mathbf{H}^{\circ} \\
\left(\mathrm{kJ} \cdot \mathrm{mol}^{-1}\right)\end{array}$ \\
\hline $0.5 \mathrm{M}$ & 16.90 & 14.11 & -83.29 & 2.79 \\
\hline CS & 25.99 & 23.20 & -68.86 & 2.79 \\
\hline
\end{tabular}

As shown in Table 5 the enthalpy values $(\Delta \mathrm{Ha})$ are positive in the presence and absence of optimum concentration of CS extract $\left(3 \mathrm{~g} . \mathrm{L}^{-1}\right)$; this suggests that the dissolution of the tinplate process becomes more difficult and indicate the endothermic nature of tinplate dissolution [33,34]. The high value of $\Delta \mathrm{Ha}$ observed in the presence of the extract indicates its high protection compared to the uninhibited solution. This rise in enthalpy value is attributed to the adsorption inhibitor [35]. The value of $E_{a}-\Delta H$ is 2.79 around the average value of $R T$ at $331^{\circ} \mathrm{K}$, the studied domain's typical temperature, which affirms that the corrosion process is a unimolecular reaction [36]. The negative values of entropies $\left(\Delta \mathrm{S}_{\mathrm{a}}\right)$ in the presence and the absence of CS extract suggest that the activated complex is in association more than a dissociation, meaning that a decrease in disordering occurs on going from reactants to the activated complex [37, 38].

\subsection{Scanning electron microscopy and energy dispersive X-rays (SME-EDX).}

To confirm the results obtained by the gravimetric and electrochemical analysis, the microscopic analyses of SEM coupled with quantitative analyses EDX have been investigated. Figures 9 and 10 show the SEM micrographs of tinplate surface, exposed to $0.5 \mathrm{M} \mathrm{H}_{2} \mathrm{C}_{2} \mathrm{O}_{4}$ medium at $303 \mathrm{~K}$ in the presence and absence of CS extract. 


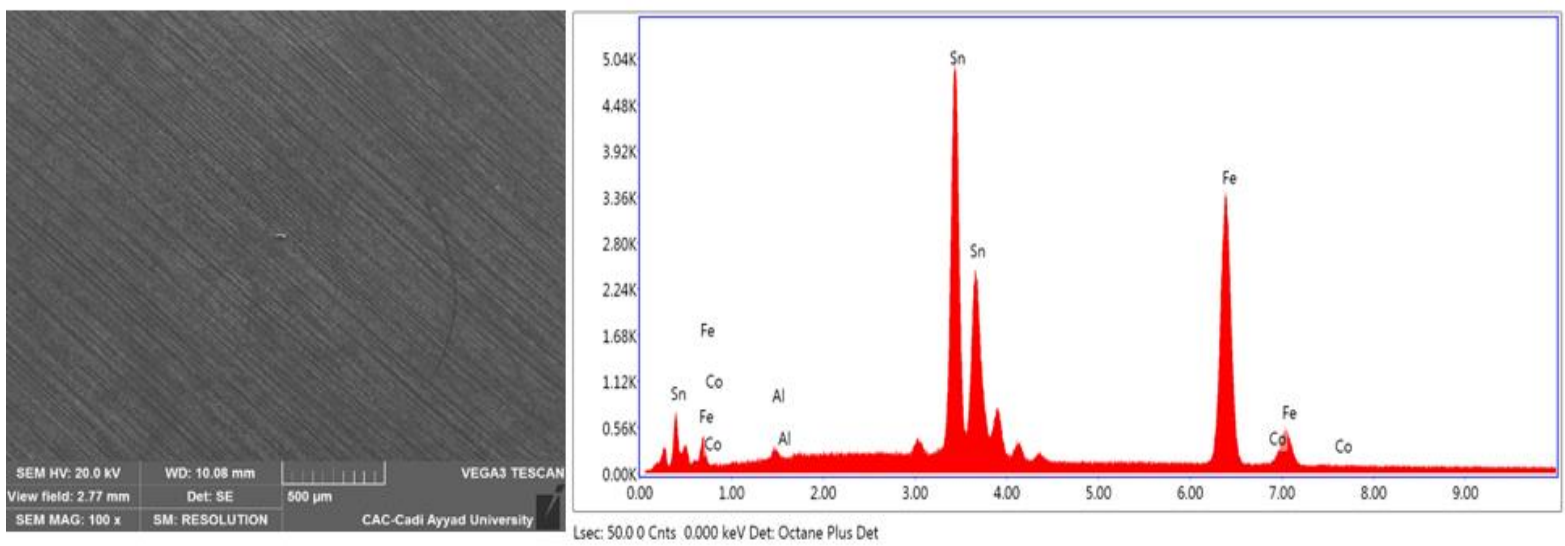

Figure 8. SEM micrograph and the EDX diagram of tinplate sheet before its immersion into $0.5 \mathrm{M} \mathrm{H}_{2} \mathrm{C}_{2} \mathrm{O}_{4}$ in the presence and absence of CS extract.
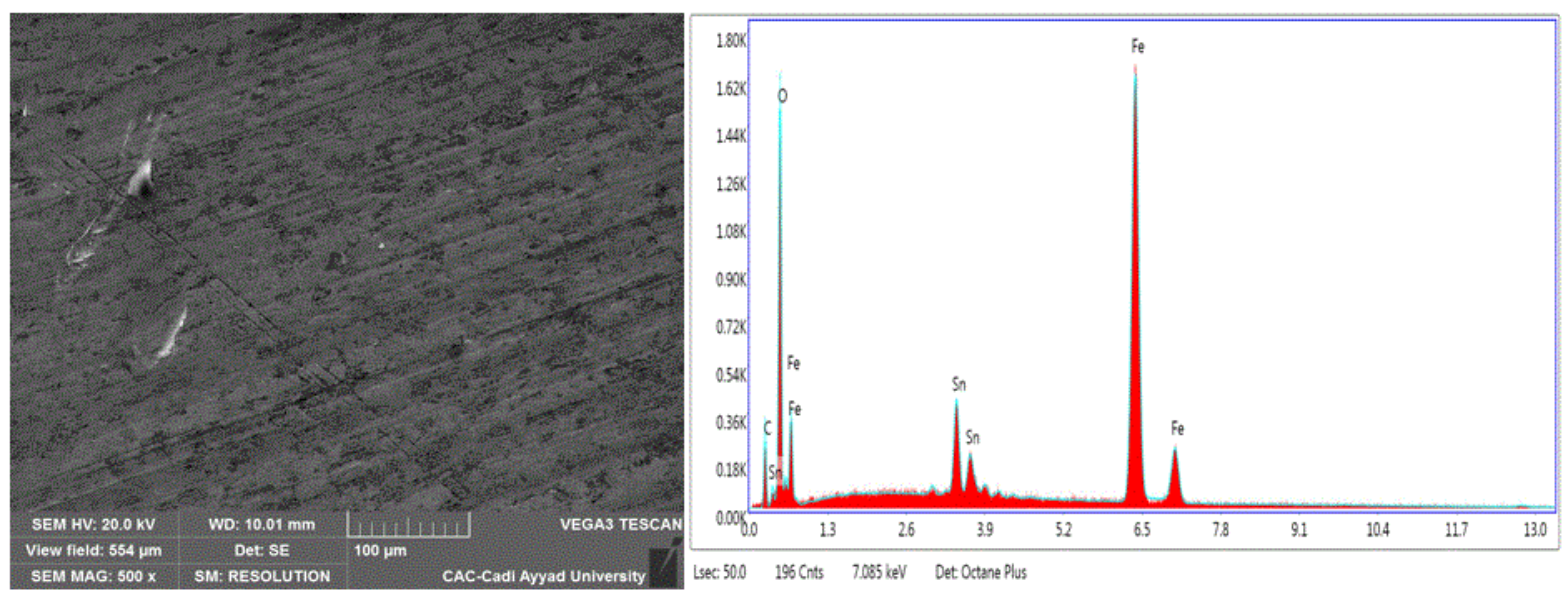

Figure 9. SEM micrograph and the EDX diagram of tinplate sheet, after its immersion into $0.5 \mathrm{M} \mathrm{H}_{2} \mathrm{C}_{2} \mathrm{O}_{4}$ for $2 \mathrm{~h}$ at $308^{\circ} \mathrm{K}$
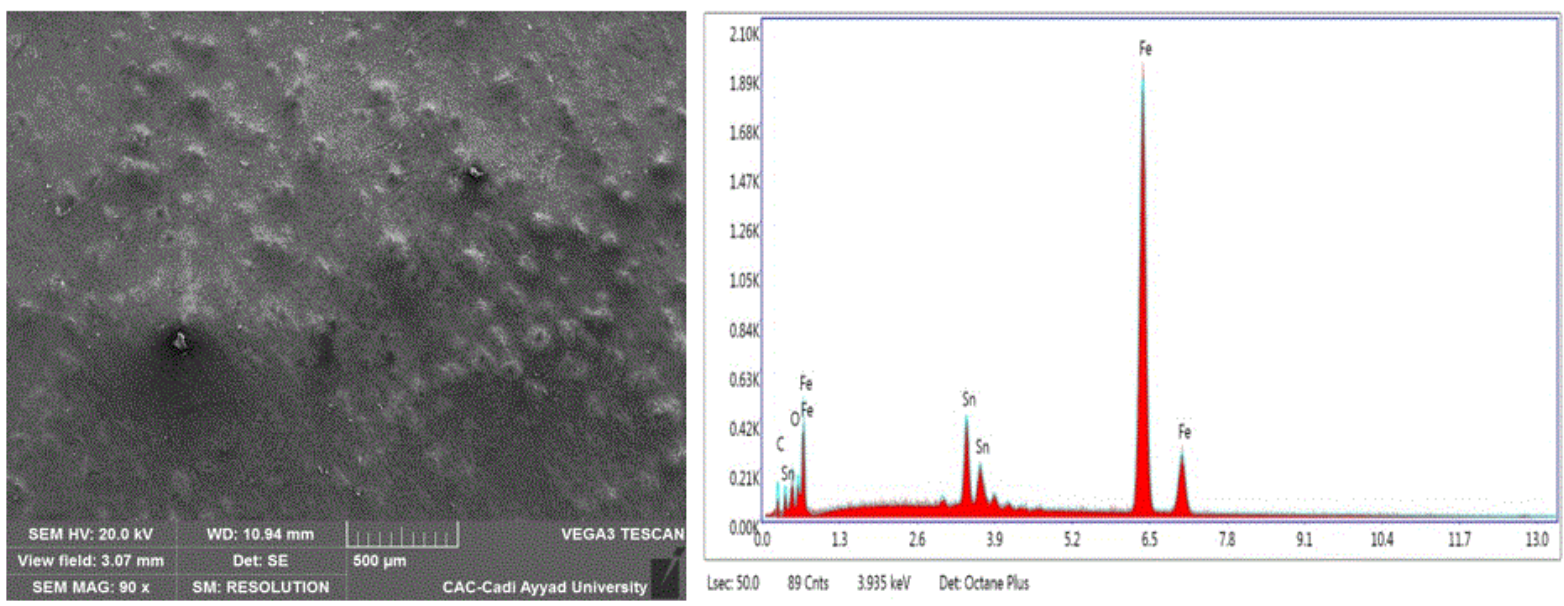

Figure 10. SEM micrograph and the EDX diagram of tinplate sheet, after its immersion into $0.5 \mathrm{M} \mathrm{H}_{2} \mathrm{C}_{2} \mathrm{O}_{4}$ with the addition of CS extract for $2 \mathrm{~h}$ at $308^{\circ} \mathrm{K}$.

Figure 9 show that the tinplate surface immersed in $0.5 \mathrm{M} \mathrm{H}_{2} \mathrm{C}_{2} \mathrm{O}_{4}$ is more attacked. In addition, the surface morphology is improved in the presence of the CS extract compared to the one in the acid medium (Figure 10). This can be explained by the existence of a protective layer formed by the adsorption of CS extract compounds. The EDX analysis displays an increase in the peaks of oxygen atoms in an inhibited medium compared to those obtained in an acid medium (Figure 10). This indicates that the oxygen atoms are strongly adsorbed onto 
the tinplate surface and justifies the inhibition performance of the CS extract. Therefore, these results confirm those obtained previously.

\section{Conclusions}

From the results presented in this research article, we conclude that aqueous extract of Crocus sativus petals can act as a good inhibitor against tinplate corrosion in $0.5 \mathrm{M} \mathrm{H}_{2} \mathrm{C}_{2} \mathrm{O}_{4}$; this is the high inhibition efficiency exhibited by this extract is $87.3 \%$ at $3 \mathrm{~g} . \mathrm{L}^{-1}$. In addition, the increasing the charge transfer resistance and decreasing in double-layer capacitance values, by increasing in the inhibitor concentration, indicate the formation of a protective layer by the adsorption of Crocus sativus extract compounds on the tinplate surface; which covers areas where the $\mathrm{H}_{2} \mathrm{C}_{2} \mathrm{O}_{4}$ solution degrades and corrodes the metal rapidly. The adsorption of the extract compounds on the tinplate surface obeys Langmuir isotherm adsorption. The results of potentiodynamic polarization curves indicate that the CS extract acts as a mixed-type inhibitor. The anti-corrosion effect of this extract can be explained by the adsorption of Crocin, which is confirmed by the increase of oxygen atoms peaks in the EDX diagram. The results obtained confirm that the CS extract could be used to prevent the corrosion of cans and maintain the quality of food conserved.

\section{Funding}

This research received no external funding.

\section{Acknowledgments}

This research has no acknowledgment.

\section{Conflicts of Interest}

The authors declare no conflict of interest.

\section{References}

1. Abdel-Rahman, N. A.-G. Tin-Plate Corrosion In Canned Foods. J. Glob. Biosci. 2015, 4, 2966-2971.

2. CODEX alimentarius commission. Codex Alimentarius Commission; 2010; 79.

3. Blunden, S.; Wallace, T. Tin in Canned Food: A Review and Understanding of Occurrence and Effect. Food Chem. Toxicol. 2003, 41, 1651-1662, https://doi.org/10.1016/S0278-6915(03)00217-5.

4. Taroco, H.A.; Garcia, E.M., Duarte, L.F.; Madeira, A.P.C.; Souza, A.G.; Taroco, C.G.; de Fátima Gorgulho, H. Factorial Design Study of Corrosion in Tin-Free Steel (TFS) Tinplate of Tomato Paste. J. Packag.Technol. Res. 2020, 4, 135-144, https://doi.org/10.1007/s41783-020-00088-8.

5. Ait Addi, B.; Ait Addi, A.; Shaban, A.; Ait Addi, E.H.; Hamdani, M. Tin corrosion inhibition by molybdate ions in $0.2 \mathrm{M}$ maleic acid solution: Electrochemical and surface analytical study. Mediterr. J. Chem. 2020, 10, 465-476, http://dx.doi.org/10.13171/mjc10502005141394aa.

6. Mora, N.; Cano, E.; Polo, J. L.; Puente, J. M.; Bastidas, J.M. Corrosion Protection Properties of Cerium Layers Formed on Tinplate. Corros. Sci. 2004, 46, 563-578, https://doi.org/10.1016/S0010-938X(03)001719.

7. Promlok, D.; Kanjanaprayut, N.; Kiatisereekul, N.; Chanthateyanonth, R.; Jariyaboon, M. Influence of food additives on blister formation in tinplate can of coconut milk. J. Food Eng. 2021, 300, 110513, https://doi.org/10.1016/j.jfoodeng.2021.110513.

8. Ninčević Grassino, A.; Grabarić, Z.; Pezzani, A.; Fasanaro, G.; Lo Voi, A. Influence of Essential Onion Oil on Tin and Chromium Dissolution from Tinplate. Food Chem. Toxicol. 2009, 47, 1556-1561, https://doi.org/10.1016/j.fct.2009.04.003. 
9. Bammou, L.; Mihit, M.; Salghi, R.; Bouyanzer, A.; Al-Deyab, S.; Bazzi, L.; Hammouti, B. Inhibition Effect of Natural Artemisia Oils towards Tinplate Corrosion in HCL Solution: Chemical Characterization and Electrochemical Study. Int J Electrochem Sci 2011, 6, 1454-1467.

10. Boumezzourh, A.; Ouknin, M.; Chibane, E.; Costa, J.; Bouyanzer, A.; Hammouti, B.; Majidi, L. Inhibition of Tinplate Corrosion in $0.5 \mathrm{M} \mathrm{H}_{2} \mathrm{C}_{2} \mathrm{O}_{4}$ Medium by Mentha Pulegium Essential Oil. Int. J. Corros. Scale Inhib. 2020, 9, 152-170.

11. Boumezzourh, A.; Ouknin, M.; Bouyanzer, A.; Costa, J.; Majidi, L. Ammodaucus Leucotrichus Cosson \& Durieu Fruits Essential Oil as Corrosion Inhibitor of Tinplate in 0.5M Oxalic Acid Medium and Its Thermodynamic Properties. Moroc. J. Chem. 2019, 7, 141-153.

12. Gikas, E.; Koulakiotis, N.S.; Tsarbopoulos, A. Phytochemical Differentiation of Saffron (Crocus sativus L.) by High Resolution Mass Spectrometry Metabolomic Studies. Molecules 2021, 26, 2180, https://doi.org/10.3390/molecules26082180.

13. Pandey, D.K.; Nandy, S.; Mukherjee, A.; Dey, A. Advances in bioactive compounds from Crocus sativus (saffron): Structure, bioactivity and biotechnology. Stud. Nat. Prod. Chem. 2020, 66, 273-304, https://doi.org/10.1016/B978-0-12-817907-9.00010-6.

14. Caser, M.; Demasi, S.; Stelluti, S.; Donno, D.; Scariot, V. Crocus sativus L. Cultivation in Alpine Environments: Stigmas and Tepals as Source of Bioactive Compounds. Agronomy 2020, 10, 1473, https://doi.org/10.3390/agronomy10101473.

15. Fahim, N.K.; Janati, S.S.F.; Feizy, J. Chemical composition of agriproduct saffron (Crocus sativus 1.) petals and its considerations as animal feed. GIDA 2012, 37, 197-201.

16. Zeka, K.; Marrazzo, P.; Micucci, M.; Ruparelia, K.C.; Arroo, R.R.; Macchiarelli, G.; Annarita Nottola, S.; Continenza, M.A.; Chiarini, A.; Angeloni, C.; Hrelia, S. Activity of Antioxidants from Crocus sativus L. Petals: Potential Preventive Effects towards Cardiovascular System. Antioxidants 2020, 9, 1102, https://doi.org/10.3390/antiox9111102.

17. Wali, A.F.; Alchamat, H.A.A.; Hariri, H.K.; Hariri, B.K.; Menezes, G.A.; Zehra, U.; Rehman, M.U; Ahmad, P. Antioxidant, Antimicrobial, Antidiabetic and Cytotoxic Activity of Crocus sativus L. Petals. Appl. Sci. 2020, 10, 1519, https://doi.org/10.3390/app10041519.

18. Maggi, L.; Carmona, M.; del Campo, C. P.; Kanakis, C. D.; Anastasaki, E.; Tarantilis, P. A.; Polissiou, M. G.; Alonso, G. L. Worldwide Market Screening of Saffron Volatile Composition. J. Sci. Food Agric. 2009, 89, 1950-1954, https://doi.org/10.1002/jsfa.3679.

19. Tarantilis, P.A.; Polissiou, M.G. Isolation and Identification of the Aroma Components from Saffron (Crocus Sativus). J. Agric. Food Chem. 1997, 45, 459-462, https://doi.org/10.1021/jf960105e.

20. Wang, Y.; Han, T.; Zhu, Y.; Zheng, C.-J.; Ming, Q.-L.; Rahman, K.; Qin, L.-P. Antidepressant Properties of Bioactive Fractions from the Extract of Crocus Sativus L. J. Nat. Med. 2010, 64, 24-30, https://doi.org/10.1007/s11418-009-0360-6.

21. Vignolini, P.; Heimler, D.; Pinelli, P.; Ieri, F.; Sciullo, A.; Romani, A. Characterization of By-Products of Saffron (Crocus Sativus L.) Production. Nat. Prod. Commun. 2008, 3, 1959-1962, https://doi.org/10.1177/1934578X0800301203.

22. Guerraf, A.E.; Titi, A.; Cherrak, K.; Mechbal, N.; Azzouzi, M.E.; Touzani, R.; Hammouti, B.; Lgaz, H. The Synergistic Effect of Chloride Ion and 1,5-Diaminonaphthalene on the Corrosion Inhibition of Mild Steel in 0.5M Sulfuric Acid: Experimental and Theoretical Insights. Surf. Interfaces 2018, 13, 168-177, https://doi.org/10.1016/j.surfin.2018.09.004.

23. Gobara, M.; Baraka, A.; Akid, R.; Zorainy, M. Corrosion protection mechanism of Ce 4+/organic inhibitor for AA2024 in 3.5\% NaCl. RSC Adv. 2020, 10, 2227-2240, https://doi.org/10.1039/C9RA09552G.

24 Bouyanzer, A.; Hammouti, B.; Majidi, L. Pennyroyal Oil from Mentha Pulegium as Corrosion Inhibitor for Steel in 1M HCl. Mater. Lett. 2006, 60, 2840-2843, https://doi.org/10.1016/j.matlet.2006.01.103.

25 Bouoidina, A.; Ech-chihbi, E.; El-Hajjaji, F.; El Ibrahimi, B.; Kaya, S.; Taleb, M. Anisole derivatives as sustainable-green inhibitors for mild steel corrosion in $1 \mathrm{M} \mathrm{HCl}$ : DFT and molecular dynamic simulations approach. J. Mol. Liq. 2021, 324, 115088, https://doi.org/10.1016/j.molliq.2020.115088.

26. Florez-Frias, E.A.; Barba, V.; Lopez-Sesenes, R.; Landeros-Martínez, L.L.; los Ríos, J.P.; Casales, M.; Gonzalez-Rodriguez, J.G. Use of a Metallic Complex Derived from Curcuma Longa as Green Corrosion Inhibitor for Carbon Steel in Sulfuric Acid. Int. J. Corros. 2021, https://doi.org/10.1155/2021/6695299.

27. Chadili, M.; Rguiti, M.M.; El Ibrahimi, B.; Oukhrib, R.; Jmiai, A.; Beelkhaouda, M.; Bammou, L.; Hilali, M.; Bazzi, L. Corrosion Inhibition of 3003 Aluminum Alloy in Molar Hydrochloric Acid Solution by Olive Oil Mill Liquid By-Product. Int. J. Corros. 2021, https://doi.org/10.1155/2021/6662395. 
28. Hamrahi, B.; Khanlarkhani, A.; Madani, S.M.; Fattah-alhosseini, A.; Gashti, S.O. Evaluation of Henna Extract Performance on Corrosion Inhibition of API 5L Steel in H2S-Containing Medium and DFT Quantum Computing of Its Constituents. Met. Mater. Int. 2020, https://doi.org/10.1007/s12540-020-00736-3.

29. Obot, I.B.; Obi-Egbedi, N.O. Ipomoea Involcrata as an Ecofriendly Inhibitor for Aluminium in Alkaline Medium: Port. Electrochimica Acta 2009, 27, 517-524, https://doi.org/10.4152/pea.200904517.

30. Ouknin, M.; Romane, A.; Ponthiaux, J.-P.; Costa, J.; Majidi, L. Evaluation of Corrosion Inhibition and Adsorption Behavior of Thymus zygis subsp. gracilis volatile Compounds on Mild Steel Surface in $1 \mathrm{~m} \mathrm{HCl}$. Corros. Rev. 2020, 38, 137-149, https://doi.org/10.1515/corrrev-2019-0055.

31. Murthy, Z.V.P.; Vijayaragavan, K. Mild Steel Corrosion Inhibition by Acid Extract of Leaves of Hibiscus Sabdariffa as a Green Corrosion Inhibitor and Sorption Behavior. Green Chem. Lett. Rev. 2014, 7, 209-219, https://doi.org/10.1080/17518253.2014.924592.

32. Salhi, A.; Bouyanzer, A.; Chetouani, A.; Barkany, S. E.; Amhamdi, H.; Hamdani, I.; Zarrouk, A.; Hammouti, B.; Desjobert, J. M.; Costa, J. Chemical Composition of Essential Oil and Antioxidant and Anti-Corrosion Activity of Extract and Essential Oil of Pennyroyal Mint (Mentha Pulegium, MP). Mor. J. Chem. 2017, 5, 59-71.

33. Majidi, L.; Znini, M.; Ansari, A.; Hammouti, B.; Jama, C.; Costa, J.; Paolini, J. Evaluation of Anticorrosive Effect of Synthesised Carveol Derivatives on Steel in Hydrochloric Acid. Int. J. Electrochem. Sci. 2013, 8, 7381-7393.

34. Ouadi, Y. E.; Beladjila, A.; Bouyanzer, A.; Kabouche, Z.; Bendaif, H.; Youssfi, F.; Touzani, R.; Chetouani, A.; Hammouti, B. The Palm Oil from Seed of Phoenix Dactylifera (Oil of Both Deglet Nour and Kentichi) as a Natural Antioxidants and Environment-Friendly Inhibitors on the Corrosion of Mild Steel in $\mathrm{HCl} 1 \mathrm{M}$. Mor. J. Chem. 2017, 5, 139-152.

35. Cristofari, G.; Znini, M.; Majidi, L.; Bouyanzer, A.; Al-Deyab, S. S.; Paolini, J.; Hammouti, B.; Costa, J. Chemical Composition and Anti-Corrosive Activity of Pulicaria Mauritanica Essential Oil against the Corrosion of Mild Steel in 0.5 $\mathrm{M} \mathrm{H}_{2} \mathrm{SO}_{4}$. Int. J. Electrochem. Sci. 2011, 6, 6699-6717.

36. Ouakki, M.; Galai, M.; Rbaa, M.; Abousalem, A.S.; Lakhrissi, B.; Touhami, M.E.; Cherkaoui, M. Electrochemical, Thermodynamic and Theoretical Studies of Some Imidazole Derivatives Compounds as Acid Corrosion Inhibitors for Mild Steel. J. Mol. Liq. 2020, 319, 114063, https://doi.org/10.1016/j.molliq.2020.114063.

37. Kharchouf, S.; Majidi, L.; Znini, M.; Costa, J.; Hammouti, B.; Paolini, J. Stereoselective Synthesis and Corrosion Inhibition Behaviour of Allyldihydrocarveols on Steel in Molar Hydrochloric Acid. Int. J. Electrochem. Sci. 2012, 7, 10325-10337.

38. Mzioud, K.; Habsaoui, A.; Ouakki, M.; Galai, M.; El Fartah, S.; Touhami, M.E. Inhibition of copper corrosion by the essential oil of Allium sativum in $0.5 \mathrm{M} \mathrm{H}_{2} \mathrm{SO}_{4}$ solutions. SN Appl. Sci. 2020, 2, 1-13, https://doi.org/10.1007/s42452-020-03393-8. 